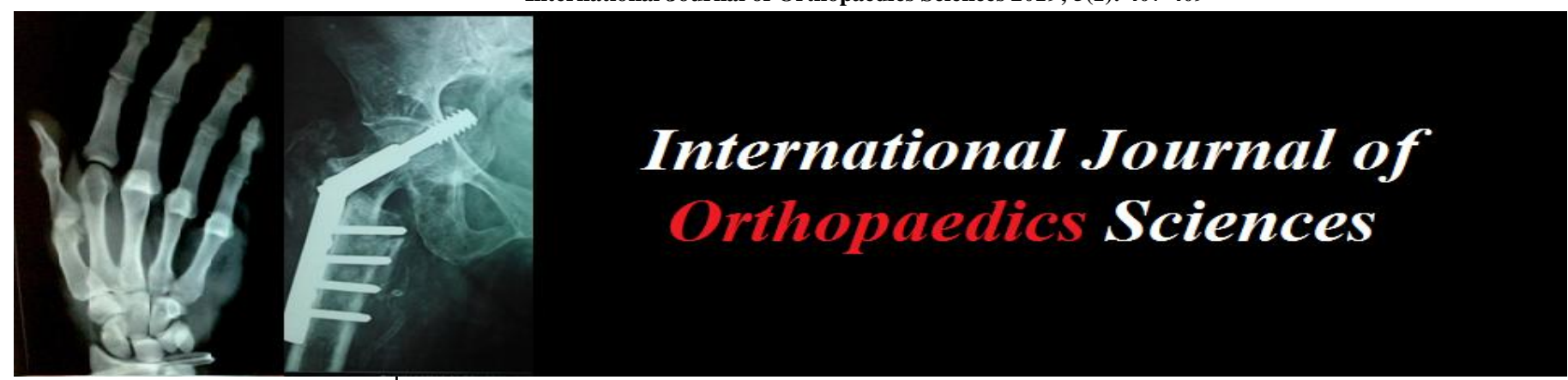

ISSN: $2395-1958$

IJOS 2019; 5(1): 407-409

(C) 2019 IJOS

www.orthopaper.com

Received: 04-11-2018

Accepted: 08-12-2018

Dr. Shri Kant Gupta

Associate professor, Department of Orthopaedics, Hind Institute of Medical Sciences Ataria

Sitapur, Uttar Pradesh, India
Correspondence

Dr. Shri Kant Gupta

Associate professor, Department

of Orthopaedics, Hind Institute

of Medical Sciences Ataria

Sitapur, Uttar Pradesh, India

\section{Assessment of cases of humerus fracture: A retrospective study}

\section{Dr. Shri Kant Gupta}

DOI: https://doi.org/10.22271/ortho.2019.v5.i1h.72

\section{Abstract}

Background: Fracture of humerus bone is on high. The chances of fracture humerus bone increases with the impact of trauma. The present study aimed at recording various humerus fractures among study group of both genders.

Materials \& Methods: The present study was conducted in the department of Orthopaedics. It comprised of 152 cases of humerus fracture of both genders. In all cases, the reason of humerus fractures was recorded. In all history, a thorough clinical examination and radiographs such as AP view and CT scan was done.

Results: Out of 152 cases, males were 102 and females were 50. The etiology of humerus fracture was road traffic accident in 88 , fall in 32 , domestic violence in 20 and physical assault in 12 . The difference was significant $(\mathrm{P}<0.05)$. The common treatment given was transosseous suture fixation $(35)$, tension band wiring (12), PHILOS plate (88) and standard plate (17).

Conclusion: Humerus bone fracture is common among road side accidents. Common treatment includes transosseous suture fixation, tension band wiring, PHILOS plate and standard plate.

Keywords: fracture, humerus, transosseous

\section{Introduction}

Road traffic accidents are major reason for deaths worldwide. Fracture of humerus bone is on high. The chances of fracture humerus bone increases with the impact of trauma. It comprise of $10 \%$ of all fractures population. These are the third most frequent fractures in patients $\geq 65$ years, following wrist and femoral neck fractures. The other reason than road side accidents could be pathologic fractures favored by osteoporosis ${ }^{[1]}$.

There has been high incidence of humerus fracture among women because of higher osteoporosis rate in women than men. Some studies have found higher mortality in PHF than in other types of fractures. Various risk factors have been implicated such as comorbidity, osteoporosis, older age and falls, are found in $>75 \%$ of these fractures. Numerous studies have shown different fracture rate. It has been reported to be $10-24 \%{ }^{[2]}$.

Fractures of proximal humerus are still unsolved fractures. Numerous fixation techniques are present and none is ideal for all cases. These fractures can be displaced, unstable and may have disruption of the blood supply ${ }^{[3]}$. The treatment of these fractures is therefore a therapeutic challenge. The majority of patients with this fracture are elderly, hence osteoporotic or brittle. Treatment options include transosseous suture fixation, tension band wiring, percutaneous wire, screw fixation, standard plate, precontoured locking plate, PHILOS plate and hemireplacement arthroplasty ${ }^{[4]}$. The present study aimed at recording various humerus fractures among study group of both genders.

\section{Materials \& Methods}

The present retrospective study was conducted in the department of Orthopaedics. It comprised of 152 cases of humerus fracture of both genders. The study protocol was approved from the institutional ethical committee. All patients were informed regarding the study and written consent was obtained.

General information such as name, age, gender etc. was recorded. In all cases, the reason of humerus fractures was recorded. In all history, a thorough clinical examination and 
radiographs such as AP view and CT scan was done. Results thus obtained were subjected to statistical analysis. $\mathrm{P}$ value less than 0.05 was considered significant.

\section{Results}

Table I: Distribution of patients

\begin{tabular}{|c|c|c|}
\hline \multicolumn{3}{|c|}{ Total- 152 } \\
\hline Gender & Males & Females \\
\hline Number & 102 & 50 \\
\hline
\end{tabular}

Table I shows that out of 152 cases, males were 102 and females were 50.
Table II: Etiology of humerus fractures

\begin{tabular}{|c|c|c|}
\hline Etiology & Number & \multirow{2}{*}{ P value } \\
\hline Road traffic accident & 88 & \multirow{2}{*}{0.05} \\
\hline Fall & 32 & \\
\hline Domestic violence & 20 & \\
\hline Physical assault & 12 & \\
\hline
\end{tabular}

Table II shows that etiology of humerus fracture was road traffic accident in 88 , fall in 32 , domestic violence in 20 and physical assault in 12 . The difference was significant $(\mathrm{P}<0.05)$.

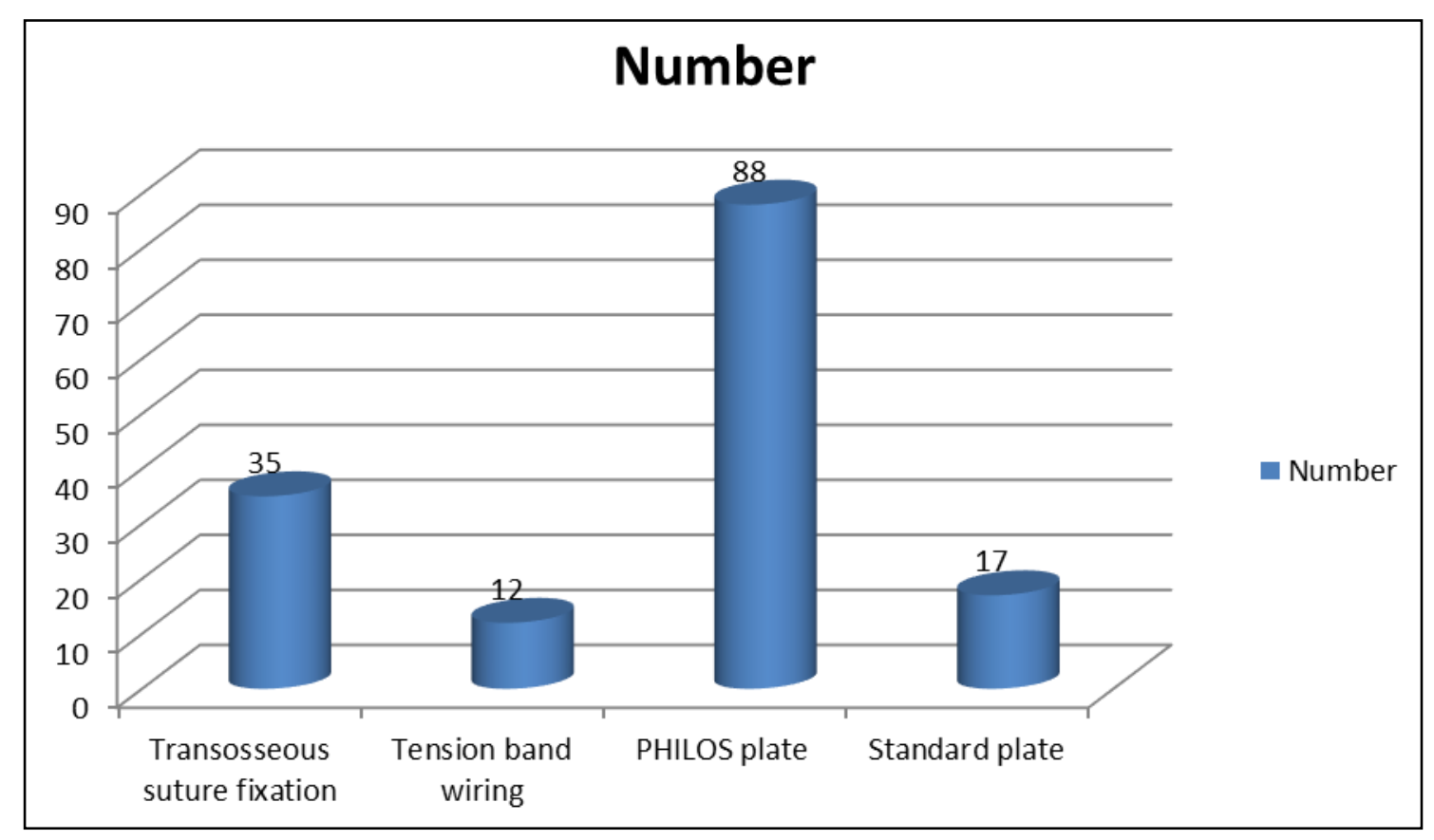

Graph I: Type of treatment

Graph I shows that common treatment given was transosseous suture fixation (35), tension band wiring (12), PHILOS plate (88) and standard plate (17).

\section{Discussion}

Humerus fracture is one of leading fracture which result from road traffic accidents, fall, domestic violence etc. Fracture of shaft of humerus represents 3 to $5 \%$ of all fractures. In case of deciding treatment option for humerus fractures, the pattern of the fracture, the displacement of these segments, patient characteristics surgeon and implant availability, local traditions and guideline etc. was considered favourable ${ }^{[5]}$. Segment fractures are mostly non-operative treated. For 2 segments fractures treatment options include closed reductions of fracture with internal fixation (CRIF) or open reduction of fracture with internal fixation (ORIF). 3 and 4 segments fractures are usually treated with ORIF or Partial Shoulder Replacement (PSR) ${ }^{[6]}$. The present study aimed at recording various humerus fractures among study group of both genders.

We found that out of 152 cases, males were 102 and females were 50. The etiology of humerus fracture was road traffic accident in 88 , fall in 32 , domestic violence in 20 and physical assault in 12 .

Sarmiento et al. ${ }^{[7]}$ conducted a study among patients admitted for fracture shaft of humerus. Out of 35 cases, $4(11 \%)$ were proximal third, $28(80 \%)$ were middle third and $3(9 \%)$ were distal third. The fractures united in $33(94 \%)$ patients whereas $2(6 \%)$ cases developed non union due to deep seated infection and one (3\%) showed delayed union. Full range of mobility of shoulder and elbow joints was present in $32(91 \%)$ patients and $3(9 \%)$ patients had stiffness of shoulder and elbow joint. The successful treatment of a humeral shaft fracture may not end with bony union: as "holistic" approach to patient care and a knowledge of anatomy, surgical indications, techniques and implants, and patient functions and expectations.

In present study, common treatment given was transosseous suture fixation (35), tension band wiring (12), PHILOS plate (88) and standard plate (17). Various advantages of PHILOS plate has been implicated. The benefits of PHILOS plate are that it gives enhanced purchase in osteopenic bone, there is no loss of reduction valgus angulations, the locking screws into the plate provides angular and axial stability of the construct. Positioning the plate too high can also lead to incorrect placement of the divergent screws in the humeral head ${ }^{[8]}$. Tytherleigh et al. ${ }^{[9]}$ in their study found that out of 205 cases of humerus fractures, there was non union in 5 cases and delayed union in 4 cases. Treatment given was precontoured locking plate, PHILOS plate and hemireplacement arthroplasty, transosseous suture fixation, tension band wiring, percutaneous wire, screw fixation and standard plate. Heim D et al. ${ }^{[10]}$ identified 43,872 patients with proximal humerus fracture. In $18.3 \%$, T2DM was seen. There was high incidence rate in men and women with and without T2DM. The use of open reduction of fracture with internal fixation and arthroplasty is increasing overtime and closed reduction with internal fixation is decreasing. Presence of T2DM in women was associated with higher in-hospital mortality (OR 1.67; 95\% CI 1.29-2.15). Comorbidities, in-hospital 
complications and older age were predictors of higher inhospital mortality in both sexes.

\section{Conclusion}

Humerus bone fracture is common among road side accidents. Common treatment includes transosseous suture fixation, tension band wiring, PHILOS plate and standard plate.

\section{References}

1. Schemitsch EH, Bhandari M. Fractures of the diaphyseal humerus. In: Browner BD, Jupiter JB, Levine AM, Trafton PG, editors. Skeletal trauma, 3rd ed. Toronto: WB Saunders. 2001, 1481 -1511.

2. Brinker MR, O'Connor DP. The incidence of fractures and dislocations referred for orthopaedic services in a capitated population. J Bone Joint Surg. Am. 2004; 86:290-297.

3. Gregory PR. Fractures of the humeral shaft. In: Bucholz RW, Heckman JD editors. Rock wood and Green's fractures in adults, 5th ed. Philadelphia: Lippincott Williams and Wilkins; 2001, 973-996.

4. Mckee MD. Fractures of the shaft of the humerus. In: Bucholz RW, Heckman JD, Court-Brown CM, Koval KJ, Tornetta III P, Wirth MA editors. Rockwood and Green's Fracture in adults. 6th ed. Philadelphia: Lippincott Williams and Wilkins; 2006, 1117-1160.

5. Fears RL, Gleis GE, Seligson D. Diagnosis and treatment of complications: Fractures of the diaphyseal humerus. In: Browner BD, Jupiter JB, Levine AM, Trafton PG, editors. Skeletal Trauma, 2nd ed. Toronto: WB Saunders; 1998, 567- 578.

6. Hoppenfeld S, de Boer P. Surgical exposures in orthopaedics - the anatomic approach. 3rd ed. Philadelphia: Lippincott Williams and Wilkins, 1994, 67104.

7. Sarmiento A, Zagorski JB, Zych G. Functional bracing for the treatment of fractures of the humeral diaphysis. $\mathbf{J}$ Bone Joint Surg Am. 2000; 82:478-486.

8. Standard JP, Harris HW, McGwin G Jr. Intramedullary nailing of humeral shaft fractures with a locking, flexible nail. J. Bone Joint Surg. Am. 2003; 85:2103-2110.

9. Tytherleigh-Strong G, Walls N, McQueen MM. The epidemiology of humeral shaft fractures. J Bone Joint Surg Br. 1998; 80:249-253.

10. Heim D, Herkert F, Hess P, Regazzoni P. Surgical treatment of humeral shaft fractures- the Basel experience. J Trauma. 1993; 35:226-31. 